\title{
Split face study on the cutaneous tensile effect of 2-dimethylaminoethanol (deanol) gel
}

\author{
Isabelle Uhoda ${ }^{1}$, Najat Faska ${ }^{1}$, Caroline Robert ${ }^{2}$, Geert Cauwenbergh ${ }^{3}$ and Gérald. E. \\ Piérard $^{1}$ \\ ${ }^{1}$ Unit of Dermocosmetology Department of Dermatopathology University Medical Center of Liège, Belgium, ${ }^{2}$ Johnson E Johnson Consumers, \\ Paris, France and ${ }^{3}$ Johnson \& Johnson, New Brunswick, USA
}

Background/aims: Beyond subjective assessments, the effect of skin tensors is difficult to assess. The present 2-phase randomized double-blind split face study was designed to compare the effect of a gel containing $3 \%$ 2-dimethylaminoethanol (deanol, DMAE) with the same formulation without DMAE.

Methods: In a first pilot study, sensorial assessments and measures of the skin distension under suction were performed in eight volunteers. In a second study conducted in 30 volunteers, shear wave propagation was measured.

Results: Large interindividual variations precluded any significant finding in the first study. The DMAE formulation showed, however, a significant effect characterized by increased shear wave velocity in the direction where the mechanical anisotropy of skin showed looseness.

Conclusion: The DMAE formulation under investigation increased skin firmness.

Key words: Dimethylaminoethanol - shear wave propagation - tensile strength - acetylcholine

(C) Blackwell Munksgaard, 2002

Accepted for publication 22 May 2001
$\mathrm{O}$ BJECTIVATING the effect of so-called skin tensors is notoriously difficult. Skin as a load-transmitting composite is subjected to the combined and variable effects of both intrinsic and extrinsic forces. A skin tensor should theoretically modify the anisotropic intrinsic cutaneous tensile strength and/or alter the sensorial perceptions of the skin tension by the subjects. Increasing the skin firmness could be achieved by modulating dermal smooth muscle contraction or by increasing the contractility and adhesion of other epidermal and dermal cells. Acetylcholine, its precursor choline and 2-dimethylaminoethanol (deanol, DMAE) a synthetic analogue of the latter $(1,2)$ are good candidates for such an effect. Indeed, cholinergic cell-surface receptors modulate a wide variety of cellular activities including proliferation, differentiation, migration and viability. Keratinocytes, melanocytes, endothelial cells, pericytes and fibroblasts possess receptors and/or cholinergic enzymes of the nicotinic and/ or muscarinic classes (3-7). These cells may form a local signal transduction network with acetylcholine as a common cytotransmitter mediating communications between different cell types. Indeed, free non-neuronal acetylcholine has been shown to be present in significant amounts in the skin (8).

This randomized double-blind split-face trial was designed to compare a gel formulation containing DMAE with the vehicle without DMAE. The tensile properties of facial skin were measured using both the suction method $(9,10)$ and a shear wave propagation test $(11,12)$. In addition, the threshold level of a suction force as perceived by the volunteers (13) was also assessed.

\section{Volunteers and Methods}

The first phase of the trial involved eight healthy adult volunteers aged from 26 to 53 years. The two formulations enriched in 3\% DMAE or not were applied each on one cheek. Ten minutes later, objective measurements of the skin sensorial 
properties were obtained using a Cutometer SEM 474 (C + K Electronic, Cologne) equipped with a $2 \mathrm{~mm}$ hollow probe. The method was described in detail earlier (13). In short, a progressive increase in suction from 0 to $500 \mathrm{mbar}$ was applied to the skin at a rate of $20 \mathrm{mbar} / \mathrm{s}$ in order to record the lowest pressure variation detected by each panelist. Skin distension was recorded both at the level of sensorial detection and at $500 \mathrm{mbar}$ suction.

A total of 30 healthy women aged from 36 to 49 years were enrolled in the second phase of the trial. All of them had a body mass index (weight/ height ${ }^{2}$ ) ranging from 19.3 to 22.9 (N: 18.7-23.8), which had been maintained almost constantly over the past five years. Resonance running time measurements (RRTM) were recorded using the prototype Reviscometer ${ }^{\circledR}$ RVM 600 (C + K Electronic, Cologne, Germany). The probe of the device was equipped with two needle-like sensors. When placed onto the skin, one needle transmitted ultrasound shockwaves and the other was the recipient. The time the waves needed to go from the transmitter to the recipient was the measured parameter RRTM expressed in arbitrary units.

The Resonance running time measurements (RRTM) measurements were taken on both cheeks before any topical application and $45 \mathrm{~min}$ after applying a pea-size amount of the test products each on one of the two facial sites. On each of the test sites, a ring was affixed onto the skin using double-sided stickers. The ring was marked with dots placed at angles $0^{\circ} / 180^{\circ}, 45^{\circ} / 225^{\circ}, 90^{\circ} / 270^{\circ}$ and $135^{\circ} / 315^{\circ}$. The proble was also marked indicating the orientation of the sensors. When placing the probe through the ring, RRTM measurements were taken in precise directions by adjusting the mark on the probe to one of the dots on the ring. Four measurements were performed in each of the four directions and averaged as the multidirectional RRTM. In addition, the lowest and highest RRTM yielded at each session and each site was recorded separately.

Skin hydration was measured on the same sites using a Dermal Phase Meter DPM ${ }^{\circledR}$ 9103, Nova, Gloucester, Mass) in the so-called immediate mode $(14,15)$. Substantivity of the test products was assessed using a Sebumeter ${ }^{\mathbb{R}}(\mathrm{C}+\mathrm{K}$ Electronic) (16).

Results were expressed as medians and range in the first study, and as means and SD in the second study. Between products, comparisons were made using the Wilcoxon matched pairs test and the paired two-tailed Student's t-test in the two studies, respectively. Significance was reached when $P$ was lower than 0.05 .

\section{Results}

\section{Study 1}

The threshold suction to perceive skin traction by the panelists was similar on the two test sites. It ranged from 150 to 500 mbar (median 360 mbar) at the site of application of the DMAE-enriched gel. On the vehicle-treated site, it ranged from 205 to 500 mbar (median 335 mbar).

The median of skin distensibility for the 500 mbar suction showed a trend to be decreased without, however, reaching significance at the DMAE treated site $(75 \mu \mathrm{m}$, range $30-170 \mu \mathrm{m})$ compared to the vehicle-treated site $(105 \mu \mathrm{m}$, range 20-180 $\mu \mathrm{m})$.

\section{Study 2}

Data on shear wave propagation are shown in Fig. 1. At entry in the study, RRTM values were similar on the symmetrical test sites. The placebo formulation appeared to have little or no effect on the mean, maximum and minimum RRTM. By contrast, the DMAE formulation induced a trend to decrease the multidirectional RRTM $(-4 \%$, $P=0.08)$. This was due to a significant decrease in the maximum RRTM $(-11 \%, P<0.05)$ while the minimum RRTM was unmodified.

The Sebumeter data were unaffected by any of the two formulations (Table 1). By contrast, both of them increased significantly $(P<0.001)$ the DPM values (Table 1).

TABLE 1. Sebumeter and DPM values before (TO) and 45 min after applying the formulations (T45)

\begin{tabular}{llllll}
\hline & \multicolumn{2}{l}{ Active formulation } & & \multicolumn{2}{c}{ Placebo formulation } \\
\cline { 2 - 3 } \cline { 5 - 6 } Parameter & T0 & T45 & & T0 & T45 \\
\hline Sebumeter & $217 \pm 44$ & $213 \pm 39$ & & $218 \pm 43$ & $215 \pm 37$ \\
DPM & $225 \pm 32$ & $489 \pm 83$ & & $225 \pm 28$ & $484 \pm 87$ \\
\hline
\end{tabular}




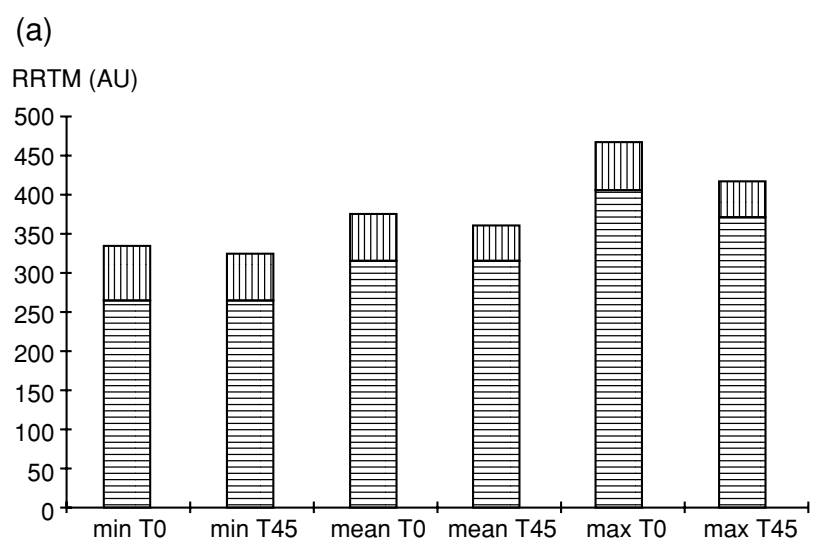

(b)

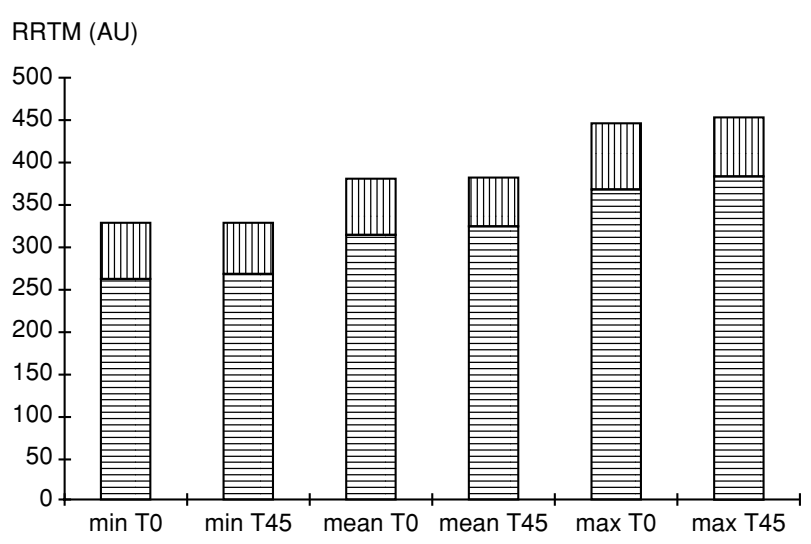

Fig. 1. Mean and SD of resonance running time measurements (RRTM) expressed in arbitrary units (AU) as assessed before (TO) and $45 \mathrm{~min}$ (T45) after topical application of the test products. The minimum (min), maximum (max) and mean multidirectional RRTM were recorded. (a) Deanol (DMAE)-treated site. The maximum RRTM is significantly $(*, P<0.05)$ decreased. (b) Placebo-treated site.

\section{Discussion}

The first pilot study conducted on a small number of volunteers was inconclusive to show a tensor effect of the DMAE formulation compared to its placebo. Indeed, large interindividual variability was yielded in the perception of the skin distension and in the actual skin distension under a given suction. Hence, a large number of volunteers would have been necessary using the same method to expect reaching statistical difference between the DMAE and placebo formulations.

The second study was conducted on a larger number of volunteers and involved recent technical improvements in measuring shear wave propagation in the skin $(11,12)$. Reproducibility of the Reviscometer ${ }^{\circledR}$ RRTM has been shown to be high with a coefficient of variation $\mathrm{CV}$ in the range $6.7-13.6 \%$ in unidirectional measurements on human skin (11). Testing on silicone gel yielded higher reproducibility values with an average variability as low as $1.2 \%$ (12). Indeed, RRTM is inversely proportional to the speed of propagation of the emitted ultrasound wave at the skin surface and to the density and intrinsic tensions inside the skin $(11,12,17-20)$. As a result, skin tension lines (21-25) influence RRTM (11). The advantage of the Reviscometer ${ }^{\circledR}$ is the easiness to collect specific directional and also multidirectional RRTM, thus allowing the assessment of the skin tension lines (minimum RRTM), the firmness laxity $^{-1}$ of skin (maximum RRTM), the average tensile strength (multidirectional RRTM) and mechanical anisotropy (RRTM coefficient of variation) (12).

Data from the present study indicate that the DMAE formulation exhibits a significant effect by increasing the shear wave velocity in the direction where it was the slowest (decreased maximum RRTM). Such a finding suggests increased firmness or tensor effect restricted to the loose tensile characteristics of the skin. The multidirectional RRTM was less discriminatory between formulations. No between-product difference was yielded for the minimum RRTM. In order words, the skin tensions along the Langer's lines and the resting skin tension lines (17-21) were kept unmodified. In sum, the mechanical anisotropy was decreased at the DMAE test site.

It was previously shown that a progressively larger proportion of aged subjects exhibit higher values of maximum RRTM as well as mean and CV of the multidirectional RRM (12). This indicated a decreased firmness of the skin and an increased mechanical anisotropy, respectively. This study clearly showed a wide range of interindividual differences in the severity of such manifestations of cutaneous ageing. These differences increased with the successive decades thus providing evidence that skin slackness and mechanical anisotropy increased with age at different rates according to the individuals (12). The mechanism involved in DMAE efficacy on the skin tensile strength is unsettled. The acetylcholine pathways are possible at the level of the neuromuscular junction and/or by increasing the contractility of non-muscular epidermal and dermal cells.

The presently reported DMAE effect upon the intrinsic tensile strength of the skin cannot be 
ascribed to changes in the hydration-related visco-elastic properties of the stratum corneum. Indeed, the hydration and lipid measurements wee similar for both formulations. However, DMAE could permit a repartioning of water in cellular membranes and in the matrix macromolecules of the dermis. Enhancing water retention in the superficial connective tissue would increase its firmness resulting in tightening of the skin surface.

In conclusion, measuring the shear wave velocity using a precise and sensitive device can be a useful tool to objectively assess some specific aspects of skin looseness and of its treatments. Skin slackness characterized by larger values of the maximum and mean multidirectional RRTM can be decreased by topical applications of DMAE. Mechanical skin anisotropy is decreased in the same subjects.

\section{References}

1. Jope RS, Jenden DJ. Dimethylaminoethanol (deanol) metabolism in rat brain and its effect on acetylcholine synthesis. J Pharmacol Exp Ther 1979; 211: 472-479.

2. Haubrich DR, Gerber HH, Pflueger AB. Deanol affects choline metabolism in peripheral tissues of mice. J Neurochem 1981; 37: 476-482.

3. Grando SA, Horton RM, Pereira EF et al. A nicotinic acetylcholine receptor regulating cell adhesion and motility is expressed in human keratinocytes. J Invest Dermatol 1995; 105: 774-781.

4. Grando SA, Horton RM, Mauro TM et al. Activation of keratinocyte nicotinic cholinergic receptors stimulates calcium influx and enhances cell differantiation. J Invest Dermatol 1996; 107: 412-418.

5. Grando SA. Biological functions of keratinocyte cholinergic receptors. J Invest Dermatol Symp Proc 1997; 2: 41-48.

6. Nodoye A, Buchi R, Greenberg B et al. Identification and mapping of keratinocyte muscarinic acetylcholine receptor subtypes in human epidermis. J Invest Dermatol 1998; 111: 410-416.

7. Buchli R, Ndoye A, Rodriguez G, Zia S, Webber RJ, Grando SA. Human skin fibroblasts express $\mathrm{m} 2,34$ and 35 subtypes of muscarinic acetylcholine receptors. J Cell Biochem 1999; 74: 264-277.

8. Klapproth H, Reinheimer T, Metzen J et al. Non-neuronal acetylcholine, a signalling molecule synthesized by surface cells of rat and man. Naunyn-Schmiedebergs Arch Pharmacol 1997; 355: 515-523.

9. Piérard-Franchimont C, Cornil F, Dehavay J et al. Climacteric skin ageing of the face. A prospective longitudinal intent-to-treat trial on the effect of oral hormone replacement therapy. Maturitas 1999; 32: 87-93.

10. Piérard GE. The EEMCO group. EEMCO guidance to the in vivo assessment of tensile functional properties of the skin. Part 1: Relevance to the structures and ageing of the skin and subcutaneous tissues. Skin Pharmacol Appl Skin Physiol 1999; 12: 352-362.

11. Nizet JL, Piérard-Franchimont C, Piérard GE. Influence of the body posture and gravitatioal forces on shear wave propagation in the skin. Dermatology 2001; 202: 177-180.

12. Hermanns-Lê T, Jonlet F, Scheen A, Piérard GE. Age and body mass index-related changes in cutaneous shear wave velocity. Exp Gerontol 2001; 36: 363-372.

13. Martalo O, Henry F, Piérard GE. Seuil liminaire de la perception d'un étirement cutané. Ann Dermatol Venereol 2001; 128: 119-122.

14. Paquet P, Piérard-Franchimont C, Fumal I et al. Sensitive skin at menopause; dew point and electrometric properties of the stratum corneum. Maturitas 1998; 28: 221-227.

15. Van Cromphaut I, Fumal I, Jacquemin D et al. Skin barrier repair after burns. Electrometric evaluation using the passive sustainable hydration test. J Envir Med 1999; 1: 47-50.

16. Piérard GE, Piérard-Franchimont C, Marks $R$ et al. EEMCO guidance for the in vivo assessment of skin greasiness. Skin Pharmacol Appl Skin Physiol 2000; 13: 372-389.

17. Potts RO, Chrisman DA, Burns EM. The dynamic mechanical properties of human skin in vivo. J Biomech 1983; 16: 365-372.

18. Potts RO, Buras EM Jr, Chrisman DA. Changes with age in the moisture content of human skin. J Invest Dermatol 1984; 82: 97-100.

19. Davis BR, Bahniuk E, Young JK et al. Age dependent changes in shear wave propagation through human skin. Exp Gerontol 1989; 24: 202-210.

20. Vexler A, Polyansky I, Gorodetsky R. Evaluation of skin viscoelasticity and anisotropy by measurement of speed of shear wave propagation with viscoelasticity skin analyzer. J Invest Dermatol 1999; 113: 732-739.

21. Langer K. Zur Anatomie und Physiologie der Haut. III-Uber die Elasticität der Cutis. Sitzeungsber Math Cl Kaiserlich Acad Wiss 1862; 45: 156.

22. Borges AF, Alexander JE. Relaxed skin ension lines, Z-plasties on scars, and fusiform excision of lesions. Br J Plast Surg 1962; 15: 242-254.

23. Borges AF. Relaxed skin tension lines (RSTL) versus other skin lines. Plast Reconstr Surg 1984; 73: 144-150.

24. Alexander $\mathrm{CH}$, Cook $\mathrm{TH}$. Accounting for the natural tension in the mechanical testing of human skin. J Invest Dermatol 1977; 69: 310-314.

25. Piérard GE, Lapière CHM. Microanatomy of the dermis in relation of relaxed skin tension lines and Langer's lines. Am J Dermatopathol 1987; 9: 219-224.

\author{
Address: \\ Gérald E. Piérard \\ Department of Dermatopathology \\ CHU Sart Tilman \\ B-4000 Liège \\ Belgium \\ Tel: +3243662408 \\ Fax: +3243662976 \\ e-mail: Gerald.Pierard@ulg.ac.be
}

